\title{
An Integrated approach using VIKOR and ENTROPY methods for a Supplier selection problem
}

\author{
A.V.A R Durga Rao \\ PG Scholar, Department of Mechanical Engineering \\ V.R Siddhartha Engineering College, Vijayawada, A.P, India \\ N.Vijaya Sai \\ Professor and Head, Department of Mechanical Engineering \\ V.R Siddhartha Engineering College, Vijayawada, A.P, India \\ K. Prakash Babu \\ Assistant Professor, Department of Mechanical Engineering \\ V.R Siddhartha Engineering College, Vijayawada, A.P, India
}

\begin{abstract}
Choosing an appropriate supplier to meet demand is a common problem that most manufacturing enterprises have to face. Normally, manufacturer's behavior a performance evaluation on each supplier before a new product comes into production. As MCDM methods facilitates working with both qualitative and non-qualitative data these methods are aptly suitable for this supplier selection problem. Generally used evaluation methods depends on different characteristics of a good supplier as measurement parameters. In the present work four main criteria's are taken into consideration for evaluating supplier's performance, that is product quality, service quality, delivery time and price. ENTROPY is used to determine the relative criteria weights and VIKOR is used to rank the alternatives.
\end{abstract}

Key Words: Supplier selection, Multi criteria decision making, Vikor, Entropy.

\section{I.INTRODUCTION}

In today's business world, an organization can't be focused without working in close collaboration with external accomplices. The concept of Supply Chain Management (SCM) emerged in this direction and seeks to optimally control the physical and information streams traded between all a performers in a supply chain (Aguezzoul, 2012). In today's extremely focused period, efficient supply chains gain more important to attain competitive advantage. Besides, this very aggressive condition is forcing the businesses found a long-term successful relationship with the expert organizations. Thus, today the organizations in a supply chain pay particular attention to the identification and selection among alternative supply sources. consequently a forceful supplier determination process is necessary to the success of any business which needs powerful suppliers (Chan, Kumar, Tiwari, Lau, \& Choy, 2008). Supplier selection has a critical effect on the aggressiveness of the entire supply chain network. Enterprises recognize that a large amount of direct and indirect profits can be attained from effective and well-organized supply chain management practices. Effective and accurate supplier selection judgments are substantial components for productions and logistics management in many firms to improve their managerial performance. Supply chain management involves all management exercises that can fulfill the customer needs alongside limiting the expenses of the organizations required in creating and conveying the goods and services to the customers. Supplier selection in acquisition is one of the most considered problems in supply chain management. Numerous criteria have been recognized in supplier evaluation and selection for a supply chain. Predominantly, the supplier selection problem involves multiple criteria, including attractive price, high quality, in time delivery, perfect post sale service and so on. As supplier relationships created, organizations have understood the basic way of these relationships to the point that many companies refer to their suppliers as partners. Supplier selection and management of suppliers is seen as being essential for companies in keeping up an intentionally aggressive position (Chen et al., 2006). The competitive position of good suppliers consists 
not only of being the source for products and services required to generative benefit, additionally includes the environmental and societal manner in which these suppliers provide said goods and services. Supplier selection is the procedure by which a given substance picks by whom services and items will be supplied. The decision has a direct effect on productivity, as the cost of an item or service directly influences the cash flow of the company obtaining the service.

\section{LITERATURE REVIEW}

Sonmez, 2006 et al.[1] Supplier selection is a fundamental obtaining activity for many organizations. Today's consumers request for more affordable, high quality products, on-time delivery and excellent after-sale services. More recent work identifies with surveying environmental aspects of interactions with a supplier. Performance effectiveness ought to be continually scrutinized and improved to ensure that competent manpower and researchers are produced. Evaluation and selection of suppliers are a typical multiple criteria decision making (MCDM) problem including numerous criteria that can be both qualitative and quantitative.

In today's business world, a organization can't be focused without working in close coordinated effort with external partners. The concept of Supply Chain Management (SCM) emerged in this direction and seeks to ideally deal with the physical and data streams traded between all performing actors in an inventory network (Aguezzoul, 2012). In today's highly competitive era, effective supply chains achieve more important to attain competitive advantage. Moreover, this highly aggressive environment is forcing the businesses establish a long-term effective collaboration with the efficient organizations. In this manner, today the organizations in a supply chain give careful consideration to the recognizable proof and selection among alternative supply sources. Therefore an effective supplier selection process is essential to the accomplishment of any business which needs effective suppliers (Chan, Kumar, Tiwari, Lau, \& Choy, 2008). Supplier selection critically affects the intensity of the entire supply chain network. Look into results show that the supplier selection prepare emits an impression of being the most significant variable in choosing the success of the supply chain. Enterprises realize that a large amount of direct and indirect profits can be obtained from effective and efficient supply chain management practices. Supplier selection has incredible effect on coordination of the supply chain relationship. Effective and accurate supplier selection decisions are significant components for productions and logistics management in many firms to enhance their hierarchical execution.

Gu"lc,inBu"yu"ko"zkan 2012 et al. [2] Moreover, selection of suppliers is a standout among the most vital angles that organizations must join into their key procedures. As organizations turn out to be increasingly reliant on suppliers, the direct and indirect consequences of poor decision making in selecting the suppliers will turn out to be more basic (Chan et al., 2008). Distant from the basic criteria such as cost and quality. There are plenty source which concentrate on the supplier selection issues, and there are additionally unique methodologies based on categorical methods, data envelopment analysis, cluster analysis, case-based-reasoning systems, decision models for the final choice-phase, linear weighting models, total cost of ownership models, mathematical programming models, statistical models and artificial intelligence based models. All of the proposed methods are searching for the proper partner for cooperation in focused time terms. One of the most known and used approach is multiple criteria decision making for supplier selection procedures thanks to its ability to compare tangible and intangible criteria.

Pema Wangchen Bhutia et al. 2012 [3] Supplier selection is a multi-criteria decision making problem which consolidates both qualitative and quantitative factors. To choose the best supplier, it is basic to make an trade off between these tangible and intangible factors. In this paper a methodology to assess suppliers in supply chain cycle based on Technique for order preferences by similarity to ideal solution method (TOPSIS). Thought of some significant criteria which influence the process of supplier selection such as product quality, service quality, conveyance time and cost. Calculated the weights for every basis in view of Analytic Hierarchy Process (AHP) and then input these weights to the TOPSIS method to rank suppliers. Advantage of utilizing TOPSIS method, It is simple to utilize, It is rational and understandable, the computation processes are straight forward. It is easy to understand and permits the pursuit of best alternative criterion depicted in a simple numerical calculation. This model could be utilized for decision making optimization in supplier selection.

Dharun Kumar.P et al. 2015 [4] Selection of supplier is one of the most critical activities performed by the organization because of its strategic importance. The selection process is based on their earlier performance records. Current evaluation methods show that they are all less objective and lack accurate data processing. Traditionally used evaluation methods are based on various characteristics of good supplier measurement criteria's such as cost, quality, delivery and warranty. Grey relation is also a decision making method used under uncertainty conditions it is found to be a superior comparable approach even if small information and determine rank of the suppliers. Supplier selection problem can be solved using 
mathematical problem linear and nonlinear programming. For new supplier evaluation, it is very convenient to perform overall measurement based on each enterprise requirements. Supplier selection is done basing on the overall performance measure of all the suppliers. This method will significantly reduce the acquiring cost and increase the production proficiency and overall competitiveness.

Prasenjit Chatterjee et al. 2011 [5] An effective supplier selection process is very important for the success of any organization. Suppliers have varied strength and weakness which require careful assessment by the purchasing manager before selecting and ranking them. The supplier selection procedure is based on the establishment of various criteria's such as quality, cost, efficiency, delivery dependability, volume flexibility, information and customer service. In this paper, to solve the supplier selection problem two multi criteria decision making methods were used. The first method is VIKOR which is also called as a compromise ranking method and the other method is ELECTRE also called as outranking method. These two methods are used to rank the alternative suppliers. Both these methods can integrate the decision maker's preferences about the relative importance of different criteria. The VIKOR method can make a compromise ranking among the alternative suppliers, where as the ELECTRE method is able to search out the best and next best suppliers for a given set of suppliers. These two methods can also be used for any type of decision making problem, involving any number of qualitative and quantitative criteria and any number of alternatives.

Amir Sanayei et al. 2010 [6] The nature of supplier selection is a intricate multi criteria problem include both quantitative and qualitative factors which may be in conflict and may also be uncertain. The VIKOR method was developed to solve multi criteria decision making problems with inconsistent and different criteria's such as product quality, on-time delivery, price (or) cost, suppliers technological level and flexibility. The decision maker needs a solution that is the closest to the ideal and alternatives are evaluated according to the criteria's. In this paper linguistic values are utilized to assess the evaluations and weights for these criteria's. These linguistic ratings can be expressed in trapezoidal or triangular fuzzy numbers. This method is extremely adaptable and not only enable us to determine the outranking order of suppliers, additionally evaluate and rate the suppliers. These ratings can be used in combination with mathematical programming and different methods to deal with supplier selection in multi sourcing conditions.

Jitendra Kumar et al. 2015 [7] This paper generally focus to compare the different multi criteria decision making methods such as TOPSIS and VIKOR method for selection of alternative industrial welding machine. Both the methods are depending on an aggregate function that represents closeness to the ideal solution. VIKOR method depends on linear normalization though TOPSIS method utilized vector normalization. In this paper rank achieved by TOPSIS and VIKOR are compared by the help of SDI software tool. The relationship coefficient was calculated with the help of MINITAB programming to evaluate the rank coefficient between these two methods. TOPSIS method has the shortest distance from the ideal one and farthest from the negative ideal solution. VIKOR method helps to conclude a compromise solution that gives a maximum group utility and minimum for opponents. With the help of normalized decision matrix methods estimate criteria weights so expert judgment can be avoided by assigning weights to various attributes. TOPSIS methods indicate that this machine is the best in terms of ranking and VIKOR method indicates that it is nearest to the ideal solution. Both the methods result in same inclination of selecting an industrial welding machine.

Mohammad Saeed Zaeri et al. 2011 [8] Supplier has varied strength and weaknesses which require careful assessment by the purchasing manager before selecting and ranking them. Any provider determination methodology is to be founded on the foundation of different criteria which may include quality, cost, efficiency, delivery dependability, volume flexibility and customer service. Multi criteria decision making methods are formal approaches to structure information and decision evaluation in problem with multiple conflicting goals. Selection can be suitable candidate for MCDA outcomes are evaluated in terms of several objectives. These stated in terms of properties either desirable or undesirable developed a fuzzy multi objective linear model to overcome the vagueness of information relating to supplier evaluation and selection. Looked at the execution of strategies, including weighted target, objective programming and think about a programming technique for supplier determination. The VIKOR strategy was set up by concentrates on positioning and selecting the best option. It is a feasible solution and compromise means an agreement established by mutual concessions made between the alternatives.

Peide Liu et al [9] In this paper supplier selection is the premise of supply chain management, and is also the key variable to enhance the competitive power of a supply chain. Which combines entropy weight and an enhanced ELECTRE-III method, is proposed to manage supplier selection of supply chains. This comprises of six suppliers and nine evaluation criteria's such as Product quality, product price, service, geographical position, technology level, supply ability, economic benefits, delivery, and market impact. The objective weight was calculated based on information entropy to keep away from 
the subjectivity of weight determined, and make the evaluation result more objective and more practical. The undifferentiated threshold, and rejection threshold were defined based on the improved ELECTRE-III method, thus it can be considered that the alternatives are undifferentiated, compensated or rejected in a certain range to cure the defects of the complete compensated evaluation method; and then the harmoniousness index, the inharmoniousness index and the outranking relation were computed.

Hossein Safari et al [10] In this paper, the weights of every criterion are calculated utilizing Shannon's Entropy. After that, PROMETHEE is used to rank the suppliers. It is a quite simple ranking method in origination and application contrasted and different methods utilized for multi-criteria analysis. It consists of five suppliers and six criteria's such as Capacity, Delivery, Quality, Shipment Accuracy, Warranty Policies and Availability of Raw materials. It is well adapted to problems where a limited number of alternatives are to be ranked according to several, sometimes conflicting criteria. The execution of PROMETHEE requires two additional types of information 1. Information on the relative significance that is the weights of the criteria considered. 2. Data on the decision-makers preference function.

Reza Kiani Mavi et al [11] In this paper supplier selection in the context of supply chain risk management. In this way nine criteria of quality, on time delivery and performance history and six risks in the supply chain include supply risk, demand risk, manufacturing risk, logistics risk, information risk and environmental risk measured for evaluating suppliers. Shannon entropy is utilized for weighing criteria and fuzzy TOPSIS is applied for ranking suppliers. It depends on the concept that the chosen alternative should have the shortest distance from the positive ideal solution and the farthest from the negative ideal solution. It is regularly difficult for a decision-maker to assign a precise performance rating to an alternative for the attributes under consideration. The value of an utilizing a Fuzzy approach is to assign the relative significance of the characteristics utilizing Fuzzy numbers rather than exact numbers. In this paper, evaluated spare parts suppliers with regards to supply chain risk management. Results show that, demand side risk has the most weight and environmental risk has the least weight in supplier selection problem

\section{PROPOSED METHODOLOGY}

In this paper, the weights of each criterion are calculated using Entropy method. After that, VIKOR is utilized to rank the alternatives.

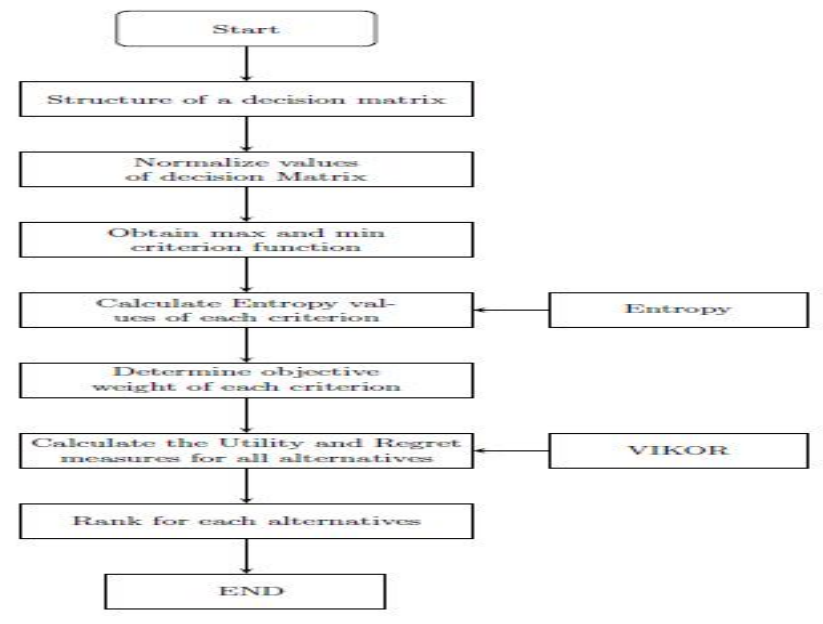

Fig 1: Flow Chart for Vikor and Entropy

\section{Entropy Method:}

In most of MCDM problems is required to have the relative importance of the criteria. This relative significance shows the importance of each criterion in regard to other criteria for decision making. There are two different methods to acquire these weights: subjective and objective weights one of the most appropriate methods to obtain the relative significance is entropy. Entropy weights are the measures of uncertainties in the information formulated using probability theory and this information content in the attribute values of the alternatives, evaluating each attributes usefulness in detecting differences in the data. 
Step 1: Normalize each criterion of the decision matrix

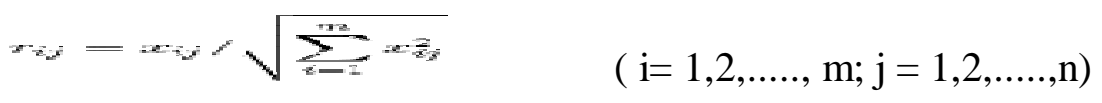

$r_{i j}$ is normalized value of $X_{i j}, X_{i j}$ is the performance measure of $i^{\text {th }}$ alternative with respect to $j^{\text {th }}$ criterion, $m$ is the number of alternatives and $\mathrm{n}$ is number of criteria.

Step 2: Calculate the entropy value $\left(\mathrm{e}_{\mathrm{j}}\right)$ of each criterion

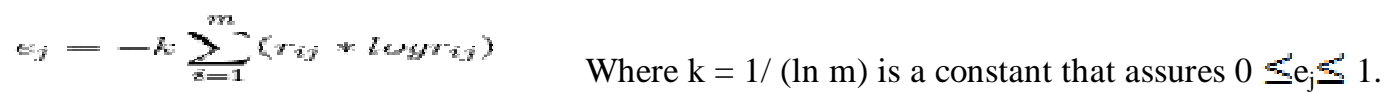

Step 3: Determine the objective weight of each criterion

\section{VIKOR Method:}

$$
\cos _{j}=1-e_{y} / \sum_{i=1}^{m e} 1-\epsilon_{j}
$$

The VIKOR method introduced by Opricovic in 1998 is an effective technique in multi criteria decision making (MCDM) which is made from the compromise programming method in solving problems with inconsistent criteria. This method lies in significant the positive and negative ideal solution. The positive ideal solution shows the alternatives with highest value while the negative ideal solution means the alternatives of lowest values. It provides a maximum group utility for the majority and a minimum of individual regret for the opponent. The compromise solution is a practical solution which is closest to the positive ideal solution and farthest from the negative ideal solution.

Step 1: Identify the major decision criteria for the alternatives

Step 2: Obtain the maximum criterion function $f_{j}^{*}$ and the minimum criterion function $f_{j}^{-}$

$$
f_{j}^{*}=f_{i j}=\max \left[f_{i j}\right]_{\mathrm{i}=1,2 \ldots, \mathrm{n}} f_{j}^{-}=f_{i j}=\min \left[f_{i j}\right]_{\mathrm{i}=1,2, \ldots, \mathrm{n}}
$$

Step 3: Calculate the utility measure and regret measure for all the alternatives

a) Utility measure

b) Regret measure

$$
\begin{aligned}
& s_{\bar{i}}=\sum\left(f_{\bar{j}}-f_{\bar{i} \dot{j}}\right) /\left(f_{\bar{j}}^{*}-f_{\bar{i}}\right) \\
& \left.\tilde{n}_{i}=\operatorname{man}:\left[\sum\left(f_{j}-f_{i}\right) / f_{j}-f_{j}\right)\right]
\end{aligned}
$$

Step 4: Calculate the value of VIKOR index for each alternative

$$
\begin{aligned}
& Q_{i}=v\left(S_{i}-S^{4}\right) /\left(S^{-}-S^{4}\right)+(1-v)\left(R_{i}-\bar{R}^{4}\right) /\left(\bar{R}^{-}-\bar{R}^{4}\right) \\
& S^{*}=S_{i}=\min \left(S_{i}\right) s^{-}=S_{i}=\max \left(S_{i}\right) \\
& \left.R^{*}=R_{i}=\min \left(R_{i}\right) R^{-}-R_{k}-\max \left(R_{n}\right) \quad \text { (Where } \mathrm{I}=1,2, \ldots \ldots \mathrm{n}\right)
\end{aligned}
$$

Normally, the value of $\mathrm{v}$ is taken as 0.5 . However $\mathrm{v}$ can take any value from 0 to 1 .

\section{IV.NUMERICAL EXAMPLE}

In the present work a numerical example by assuming expert opinions is illustrated for only evaluating the effectiveness of the methodology

Twenty suppliers basing on four criteria's that is product quality, service quality, delivery time and time were evaluated on the present work. Weights of criteria's were calculated using Entropy method and these calculated weights are used as VIKOR inputs. Finally VIKOR methodology is used to evaluate the best supplier is selected. 
Assumed expert rating for suppliers

Ten point scale is chosen for attributes are:

\begin{tabular}{ll}
\multicolumn{2}{c}{ C1 \& C2 } \\
Excellent & -10 \\
Very Good & -8 \\
Good & -6 \\
Satisfactory -4
\end{tabular}

C3

Extremely Fast - 10

Very Fast $\quad-8$

Fast $\quad-6$

Slow $\quad-4$
C4

Extremely High-10

Vey High $\quad-8$

High $\quad-6$

Reasonable - 4

Table 1: Structure of a decision matrix

\begin{tabular}{|c|c|c|c|c|}
\hline Suppliers $\mathbb{L}$ Criteria $\rightarrow$ & Product Quality $\left(\mathrm{C}_{1}\right)$ & Service Quality $\left(\mathrm{C}_{2}\right)$ & Delivery Time $\left(C_{3}\right)$ & Price $\left(\mathrm{C}_{4}\right)$ \\
\hline $\mathrm{S}_{1}$ & 10 & 6 & 8 & 6 \\
\hline $\mathrm{S}_{2}$ & 6 & 4 & 6 & 10 \\
\hline $\mathrm{S}_{3}$ & 10 & 8 & 8 & 4 \\
\hline $\mathrm{S}_{4}$ & 8 & 6 & 10 & 8 \\
\hline $\mathrm{S}_{5}$ & 4 & 10 & 4 & 6 \\
\hline $\mathrm{S}_{6}$ & 10 & 10 & 6 & 10 \\
\hline $\mathrm{S}_{7}$ & 8 & 6 & 4 & 8 \\
\hline $\mathrm{S}_{8}$ & 6 & 8 & 10 & 8 \\
\hline $\mathrm{S}_{9}$ & 10 & 6 & 6 & 10 \\
\hline$S_{10}$ & 6 & 8 & 8 & 6 \\
\hline $\mathrm{S}_{11}$ & 8 & 10 & 10 & 4 \\
\hline $\mathrm{S}_{12}$ & 4 & 4 & 10 & 10 \\
\hline $\mathrm{S}_{13}$ & 8 & 6 & 8 & 10 \\
\hline $\mathrm{S}_{14}$ & 6 & 10 & 6 & 8 \\
\hline $\mathrm{S}_{15}$ & 10 & 8 & 4 & 8 \\
\hline $\mathrm{S}_{16}$ & 10 & 8 & 8 & 4 \\
\hline $\mathrm{S}_{17}$ & 8 & 10 & 10 & 8 \\
\hline $\mathrm{S}_{18}$ & 4 & 8 & 8 & 4 \\
\hline $\mathrm{S}_{19}$ & 10 & 6 & 10 & 6 \\
\hline $\mathrm{S}_{20}$ & 6 & 8 & 6 & 8 \\
\hline
\end{tabular}

Table 2: Normalized values of decision matrix

$$
r_{i j}-x_{i j} / \sqrt{\sum_{i=1}^{m} x_{i, j}^{2}}
$$

\begin{tabular}{|c|c|c|c|c|}
\hline Suppliers $\downarrow$ Criteria $\rightarrow$ & Product Quality $\left(\mathrm{C}_{1}\right)$ & Service Quality $\left(\mathrm{C}_{2}\right)$ & Delivery Time $\left(\mathrm{C}_{3}\right)$ & Price $\left(\mathrm{C}_{4}\right)$ \\
\hline $\mathrm{S}_{1}$ & 0.2830 & 0.1734 & 0.2297 & 0.1764 \\
\hline $\mathrm{S}_{2}$ & 0.1698 & 0.1156 & 0.1723 & 0.2941 \\
\hline $\mathrm{S}_{3}$ & 0.2830 & 0.2313 & 0.2297 & 0.1176 \\
\hline $\mathrm{S}_{4}$ & 0.2264 & 0.1734 & 0.2872 & 0.2352 \\
\hline $\mathrm{S}_{5}$ & 0.1132 & 0.2891 & 0.1148 & 0.1764 \\
\hline $\mathrm{S}_{6}$ & 0.2830 & 0.2891 & 0.1723 & 0.2941 \\
\hline $\mathrm{S}_{7}$ & 0.2264 & 0.1734 & 0.1148 & 0.2352 \\
\hline $\mathrm{S}_{8}$ & 0.1698 & 0.2313 & 0.2872 & 0.2352 \\
\hline $\mathrm{S}_{9}$ & 0.2830 & 0.1734 & 0.1723 & 0.2941 \\
\hline $\mathrm{S}_{10}$ & 0.1698 & 0.2313 & 0.2297 & 0.1764 \\
\hline
\end{tabular}




\begin{tabular}{|c|c|c|c|c|}
\hline $\mathrm{S}_{11}$ & 0.2264 & 0.2891 & 0.2872 & 0.1176 \\
\hline $\mathrm{S}_{12}$ & 0.1132 & 0.1156 & 0.2872 & 0.2941 \\
\hline $\mathrm{S}_{13}$ & 0.2264 & 0.1734 & 0.2297 & 0.2941 \\
\hline $\mathrm{S}_{14}$ & 0.1698 & 0.2891 & 0.1723 & 0.2352 \\
\hline $\mathrm{S}_{15}$ & 0.2830 & 0.2313 & 0.1148 & 0.2352 \\
\hline $\mathrm{S}_{16}$ & 0.2830 & 0.2313 & 0.2297 & 0.1176 \\
\hline $\mathrm{S}_{17}$ & 0.2264 & 0.2891 & 0.2872 & 0.2352 \\
\hline $\mathrm{S}_{18}$ & 0.1132 & 0.2313 & 0.2297 & 0.1176 \\
\hline $\mathrm{S}_{19}$ & 0.2830 & 0.1734 & 0.2872 & 0.1764 \\
\hline $\mathrm{S}_{20}$ & 0.1698 & 0.2313 & 0.1723 & 0.2352 \\
\hline
\end{tabular}

Table 3: Obtain maximum and minimum criterion function

$$
f_{j}=f_{i j}=\max \left[f_{i j}\right] \quad f_{j}^{-}=f_{i j}=\min \left[f_{i j}\right]
$$

\begin{tabular}{|c|c|c|c|c|}
\hline $\begin{array}{c}\text { Measures } \downarrow \text { Criteria } \\
\rightarrow\end{array}$ & Product Quality $\left(\mathrm{C}_{1}\right)$ & Service Quality $\left(\mathrm{C}_{2}\right)$ & Delivery Time $\left(\mathrm{C}_{3}\right)$ & Price $\left(\mathrm{C}_{4}\right)$ \\
\hline $\mathrm{f}_{\mathrm{j}}^{*}$ & & & & \\
\hline $\mathrm{f}_{\mathrm{j}}^{-}$ & 0.2830 & 0.2891 & 0.2872 & 0.1176 \\
\hline
\end{tabular}

Table 4: Calculate the entropy value $\left(\mathrm{e}_{\mathrm{j}}\right)$ of each criterion

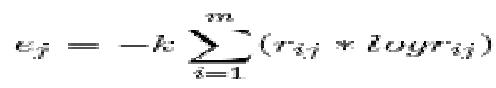

\begin{tabular}{|c|c|c|c|c|c|}
\hline $\begin{array}{c}\text { Criteria } \rightarrow \\
\text { Entropy } \downarrow\end{array}$ & $\begin{array}{c}\text { Product } \\
\text { Quality }\left(\mathrm{C}_{1}\right)\end{array}$ & $\begin{array}{c}\text { Service Quality } \\
\left(\mathrm{C}_{2}\right)\end{array}$ & Delivery Time $\left(\mathrm{C}_{3}\right)$ & Price $\left(\mathrm{C}_{4}\right)$ & Total \\
\hline $\mathrm{e}_{\mathrm{j}}$ & 0.9314 & 0.9399 & 0.9329 & 0.9295 & \\
\hline $1-\mathrm{e}_{\mathrm{i}}$ & 0.0686 & 0.0601 & 0.0671 & 0.0705 & $\sum=0.2663$ \\
\hline
\end{tabular}

Table 5: Determine the objective weight of each criterion

$$
w_{j}=1 \quad c_{i} / \sum_{i=1}^{m} 1 \quad c_{j}
$$

\begin{tabular}{|c|c|c|c|c|}
\hline Weights $\mathbb{L}_{\text {Criteria } \rightarrow}$ & Product Quality $\left(\mathrm{W}_{1}\right)$ & Service Quality $\left(\mathrm{W}_{2}\right)$ & Delivery Time $\left(\mathrm{W}_{3}\right)$ & Price $\left(\mathrm{W}_{4}\right)$ \\
\hline Weights & 0.2576 & 0.2256 & 0.2519 & 0.2647 \\
\hline
\end{tabular}

Table 6: Calculate the utility measure and regret measure for all the alternatives and Rank for each alternative

$$
\begin{gathered}
\left.s_{i}-\sum\left(f_{j}^{*}-f_{i, n}\right)\left(f_{j}^{*}-f_{i}\right) \quad R_{i}=\max \left[\sum f_{j}^{*}-f_{i j}\right) /\left(f_{j}^{*}-f_{j}^{-}\right)\right] \\
Q_{i}=v\left(S_{i}-S^{*}\right) /\left(S^{-}-S^{*}\right)+(1-v)\left(R_{i}-R^{*}\right) /\left(R^{-}-R^{*}\right)
\end{gathered}
$$

\begin{tabular}{|c|c|c|c|c|}
\hline Suppliers $\downarrow$ & $S_{i}$ & $R_{i}$ & $Q_{i}$ & Rank \\
\hline$S_{1}$ & 0.3225 & 0.1504 & 0.3427 & 5 \\
\hline$S_{2}$ & 0.8298 & 0.2647 & 1 & 20 \\
\hline$S_{3}$ & 0.1819 & 0.0979 & 0.1029 & 3 \\
\hline$S_{4}$ & 0.4232 & 0.1763 & 0.482 & 15 \\
\hline$S_{5}$ & 0.5976 & 0.2576 & 0.8242 & 13 \\
\hline$S_{6}$ & 0.4325 & 0.2647 & 0.7329 & 18 \\
\hline
\end{tabular}




\begin{tabular}{|c|c|c|c|c|}
\hline $\mathrm{S}_{8}$ & 0.4459 & 0.1763 & 0.4973 & 9 \\
\hline $\mathrm{S}_{9}$ & 0.5829 & 0.2647 & 0.834 & 16 \\
\hline $\mathrm{S}_{10}$ & 0.4189 & 0.1717 & 0.4664 & 7 \\
\hline $\mathrm{S}_{11}$ & 0.0858 & 0.0858 & 0.0498 & 2 \\
\hline $\mathrm{S}_{12}$ & 0.7475 & 0.2647 & 0.9446 & 19 \\
\hline $\mathrm{S}_{13}$ & 0.5851 & 0.2647 & 0.8355 & 17 \\
\hline $\mathrm{S}_{14}$ & 0.5158 & 0.1763 & 0.5442 & 10 \\
\hline $\mathrm{S}_{15}$ & 0.5033 & 0.2519 & 0.745 & $\mathbf{1}$ \\
\hline $\mathrm{S}_{16}$ & $\mathbf{0 . 1 5 9 1}$ & $\mathbf{0 . 0 8 4 0}$ & $\mathbf{0 . 0 4 9 2}$ & 6 \\
\hline $\mathrm{S}_{17}$ & 0.2621 & 0.1763 & 0.3737 & 12 \\
\hline $\mathrm{S}_{18}$ & 0.4167 & 0.2576 & 0.7026 & 11 \\
\hline $\mathrm{S}_{19}$ & 0.2385 & 0.1504 & 0.2863 & 0.5947 \\
\hline $\mathrm{S}_{20}$ & 0.5909 & 0.1763 & & 14 \\
\hline
\end{tabular}

\section{RESULTS AND DISCUSSIONS}

In this paper twenty suppliers are evaluated based on the specialized criteria. The result of the analysis gives the best performing supplier among twenty suppliers. The company can get a chance to improve its long term relationship with best performing suppliers to get higher performance.

To calculate the weights for every criterion depends only on Analytic Hierarchy Process (AHP). It separately takes from expert decision opinions of criterion ratings and process the pair wise comparison matrix, then calculates the weights of each criteria. Followed by utilizing these weights to determine the entire process of the method. So we minimize the pair wise comparison matrix and experts decision, opinion ratings of the criteria. Vikor method is used in this paper, because the selection of suppliers characteristics and inclination for each kind of procurement process depends on decision makers subjective judgment. It is a mathematical multi criteria decision making model. Supplier evaluation based on the qualitative criteria having an absence of data or lack of clearness about supplier execution. The compromise ranking used for any type of decision-making problem, including any number of qualitative and quantitative criteria and any number of alternatives. The advantage of this method involves a quite simple computational procedure, and it offers an efficient and logical approach to arrive at the best decision. Entropy is calculated the relative weight of each criteria only use experts decision matrix. It measure the data content in the attribute values of the alternatives, thereby evaluating each attributes usefulness in detecting differences in the data. According to results S16 is the best supplier among other suppliers.

\section{VI.CONCLUSION}

Supplier selection is a broad comparison of suppliers utilizing a typical arrangement of criteria and measures to recognize suppliers with the highest potential for meeting a firm's needs consistently and at a satisfactory cost. Selecting the right suppliers much reduces the purchasing costs and improves corporate competitiveness, therefore supplier selection one of the most important decision making problems. Supplier selection is considered as a key problem that is generally considered as an MCDM. In this paper, VIKOR is a helpful tool in multi-criteria decision making; the obtained compromise solution could be acknowledged by the decision makers because it provides a maximum group utility of the majority, and a minimum of the individual regret of the opponent. VIKOR Method supports subjective and objective weights, where subjective weights are obtained directly from the decision makers while objective weights are determined based on Entropy method. In all the methods AHP is used for calculating the weights that is considering decision maker's ratings given for criteria to criteria. Initially decision maker ratings for each criteria respective to each supplier will be given. From which pair wise comparison matrix is constructed basing upon again decision maker rating that is criteria to criteria comparison. The major difference between AHP and Entropy methods is pair wise comparison matrix is considered in AHP where as in Entropy pair wise comparison matrix is not taken into consideration it directly calculates weights on decision maker ratings matrix for each criteria respective to each supplier. This is main advantage of Entropy method. Finally, proposed a numerical example to illustrate an application of the proposed method. The results may vary with respect to expert opinions.

\section{ACKNOWLEDGMENT}

The first author expresses his gratitude to V. R. Siddhartha Engineering College, Vijayawada, Andhra Pradesh, India, for moral support to organize this research work. 


\section{REFERENCES}

[1] SONMEZ, M, A review and critique of supplier selection process and practice, Occasional Paper 2006:1. Loughborough: Business School, ISBN: 185901 1977.

[2] Gu“lc,inBu"yu"ko"zkan, An integrated fuzzy multi-criteria group decision-making approach for green supplier evaluation.International Journal of Production Research Vol. 50, No. 11, 2892-2909, 1 June 2012.

[3] PemaWangchenBhutia, Ruben Phipon, Application of AHP and TOPSIS method for supplier selection Problem, IOSR Journal of Engineering Volume 2 43-50 (October 2012).

[4] Dharun Kumar.P, Mani Bharathi Karthikeyan.S, Application of grey relation model in a supplier selection process, International journal of scientific \& Engineering Research volume 5, issue 5, May-2014,

[5] PrasenjitChatterjee, Poulomi Mukherjee, Shankar Chakraborty, Supplier Selection Using Compromise Ranking and Out Ranking Methods, J,Ind.Eng.Int, 7(14),61-73 (2011),

[6] Amir Sanayei, S.FaridMousavi, A.Yazdankhah, Group decision making process for supplier selection with VIKOR under fuzzy environment, Expert Systems with Applications 24-30, 37(2010).

[7] Jitendra Kumar, TarunSoota, Ganga Sagar Singh Topsis and Vikor approaches to machine tool selection,J. Sci. Res. Adv. Vol 2, No.3,125-130, 2015.

[8] Mohammad Saeed Zaeri, Amir Sadeghi, Amir Naderi, Application of multi criteria decision making technique to evaluation suppliers in supply chain management, african Journal of Mathematics and Computer Science Research Vol. 4 (3), pp. 100-106, March 2011,

[9] Peide Liu and Xin Zhang, Research on the supplier selection of a supply chain based on entropy weight and improved ELECTRE-III method, International Journal of Production Research Vol. 49, No. 3, 637-646, 1 February 2011.

[10] Hossein Safari, Maryam Sadat Fagheyi, Saadeh Sadat Ahangari, Applying PROMETHEE Method based on Entropy Weight for Supplier Selection, business management and strategy Vol. 3, No. 1ISSN 2157-6068 2012.

[11] Reza Kiani Mavi, Mark Goh, Neda Kiani Mavi, Supplier selection with Shannon entropy and fuzzy TOPSIS in the context of supply chain risk management, Procedia - Social and Behavioral Sciences 216 - 225, 235 ( 2016 ). 